\section{The Laundries of the Ancients*} By Henri Rousset

WE do not realize, when we use our modern methods of washing linen, that they represent centuries of labor and ingenuity, that they sum up the results of thousands of experiments. For centuries, in lack of convenient processes, people were obliged to use very inconvenient ways of laundering. It is interesting to know how these ancients of whom we are often told-Egyptians of the time of the Pharaohs, old Greeks and Romans-washed their linen. Modern historians are fond of such details which, better than official history, enable us to appreciate the character of a people; and we can find in their works some very good accounts of the state of the laundry art in the old ages. Of course, numerous details are lacking,
but the chief features are known. We shall describe them, suppressing purposely all worthless display of erudition.

\section{Materials USED}

The launderer of the ancient Egypt could use neither soap nor Javelle water. Before studying his process, we must first know the products he has at his disposal. Those were relatively numerous. Among the natural products known in antiquity and used in the different arts were
alkali, etc.

Clay and Chalk.-Several mines were exploited to produce the variety of clay used in the cloth industry, to clean and to fill woolen fabrics. The best clay was named cimolia, because found in the Cimolos Island, one of the Cyclads. Other varieties came from Italy (umbrica terra), from Sardinia (sardo), from Samos and Lemnos. They were employed not only for cleaning, but also for sizing woolen fabrics. Some of these products were chalks rather than clays. Tournefort, during his travel in Milo Island, analyzed cimolia which was found to be almost pure carbonate of calcium. The peasants of Cimolos still use this product instead of soap to wash their linen.

Vegetable Powders.-The absorbing vegetable powders still used in some detergent preparations (to remove the greasy stains) were employed by the Romans to clean fabrics. Caelius mentions the lomentum (lima bean or pea flour) as a good cleaning agent, which, however, was more often used for washing the face than to clean e clothes.

Alkalies.-Wood ashes are mentioned in Aristophanes' and Plato's works as products used in washing. The most efficacious solution was prepared from the the ashes of the fig trees and grape vines. Under the name of nitrum, the Roman artisans used also products containing large proportion of carbonate of sodium and potassium. Almost all the nitrum came from Egypt, where there were natural layers, and several mines. Very considerable quantities were consumed, not only to clean, but also to produce glass, dyes, drugs, etc.

The urine was used in Rome to clean clothes; after fermentation the liquid becomes rich in ammonia and can replace a solution of ammonia. This Roman use of urine is very well known, because one of the Latin emperors put a tax on the urine collected in vases placed by the cleaners in different public places. Tradition relates that this emperor replied to his son who was disgusted with seeing the state collect money from such a source, "Money does not smell, my son."

Soap.-The ancients did not know soap. What the Latins called sapo was not a product like our modern soap, but a mixture of grease and wood ashes, containing an excess of unneutralized alkali. This sapo was not a cleaner, but a cosmetic, used to make blond the hair of the Latin brunette.

Saponius.-The roots of the saponaria were used in Greece and Latin empires. The plant was known by the name radix lamaria and herba lamaria; but it is pre-
sumed that it was not used in the laundry. but only to clean the wool in the grease.

\section{METHODS OF WASHING}

Ancient Egypt.-The specialists in the history of old Egyptian daily life seem not to be very well informed about the methods of washing of these times, although good methods were certainly used, because we know they not only washed, but sized the linen. In the Florence Museum is kept a kind of board engraved with parallel small furrows, which was used to produce a special finish upon the pieces of clothes. Erman notes that in the Pharsonic court was a chief washer, a very imFortant officer, and gives the reproduction of an Egyptian picture of the middle empire, with this explanatory note: "We see the washers beating the wet clothes with wooden staves; they sprinkle them holding their arms up high. They hand one end of the folded piece of linen over a post, put a stick through the other end, and wring it with a good deal of force. They then stretch and fold up the linen and finally the chief packs it up in a great bundle." We give herewith the reproduction of the ex plained picture.

Ancient Greece.-In the ancient Greece the clothes were washed in special basins, built in the river bank or near a spring. Here the pieces were tramped with the feet, to expel the dirt. The best poet of all ages, Homer told in his Odyssey of a Grecian laundry, operated by the Princess Nausicaa, daughter of the Phaecian king. "Father," the girl said, "would you not order a large "Frriage, to carry our dirty clothes to the river, in order to enable me to wash them? Seated the first in the council, you must wear clean clothes; and my brothers must have clean clothes, too, to go to the dance." In reality, the girl wished especially to have her own clothes clean, because she hoped to become engaged very soon but as a princess, she was very "diplomatic." The king father having agreed, Nausicaa and her girl servant went to the river. "There," the poet said, "were cisterns filled all the year with water good for cleaning

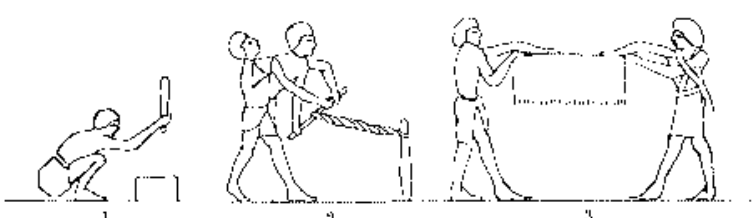

Egyptian Method of Washing. 1-Washing; 2-Wringing; 3-Folding

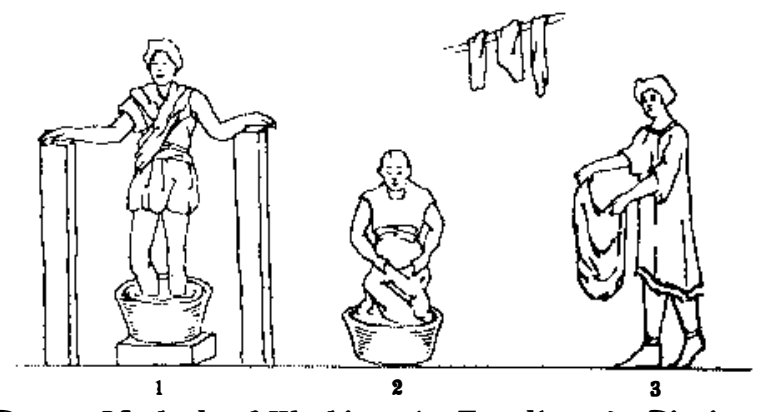

Roman Methods of Washing. 1-Treading; 2 - Rinsing ;
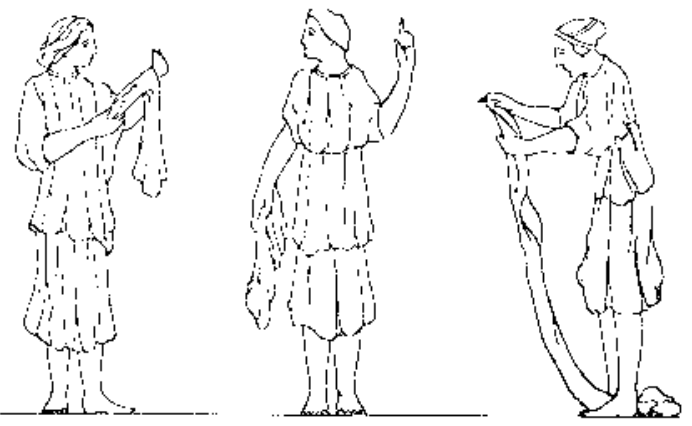

Grecian Women at Laundry Work

all soiled articles. The girl plunged the clothes into the deep water and tramped them; afterward they spread them on the rocks of the shore-and the clothes dried under the sun splendor." From the pictures on some ancient vases, we can see that the pieces were wrung by hand, a process which is still used in many countries.

The Homeric process concerns the prehistoric Greece. Later, in the Grecian cities the methods used to wash linen were the same as in Rome. In both places, proessional cleaners applied them. We know that in Athens there were professional launderers, the trade being followed by both men and women. They charged very low prices. Aristophanes mentions in one of his comedies that it costs only ten cents to clean a coat. It is true that the Grecian clothes were, as well known, of very simple form. A piece of fabric, just draped on the body, sometimes constituted a whole suit.

Ancient Rome.-In Rome, the washing of clothes was never-at least in historical times-done at home, except in the houses of some patricians, who were rich enough to maintain a professional shop for the use of their family, servants and perhaps "clients." All the clothes being made of wool, the cleaning of worn pieces was done by the same method as the cleaning and sizing of fabrics just from the loom. The fullones who did the work were organized in powerful corporations, owning important shops, with large tanks and pipe systems
to furnish water, etc. They washed by treading the pieces placed in baths of water and clay or chalk, or fermented urine, etc. After rinsing, the white articles ere exposed to the action of sulphurous anhydride produced by burning sulphur in the air of a small closed chamber, made with sticks of wicker, assembled in th form of a big bell. The clothes covered the sticks and the sulphur burned in the center of the bell. Finally, the fabrics were sized by scratching regularly their surface with special kind of thistle and by rubbing with certain kinds of chalk. At last, the pieces, lightly dampened with water 'blown in small drops from the mouth, were pressed with a special apparatus.

Pliny says that in the old period of the ancient Rome, two "censors" proposed a law, which was adopted by the people, to regulate the trade of the "fullones." The official process, which was made compulsory to avoid any dishonest competition is described as follows: (1) Washing with terra sarda and water; (2) fumigating white articles with burning sulphur; (3) rubbing with terra crimolia for colored garments, terra saxum for white pieces. Afterwards the law became obsolete and the fullones had all liberty of managing the cleaning as they wished to. In general, they always chiefly operated by treading the pieces placed in small basins, as we can see from the contemporary fresco, discovered in a Pompeiian home, of which some pictures are reproduced here.

We can see that the "fullones" were rather more cleaners than launderers. They worked so well that sometimes it was impossible to distinguish an old article from a new one. However, they charged very reasonably, and often the Roman customers paid a fixed amount by the year to the nearest cleaner's shop to have all necessary cleansing done for them.

\section{Origin and Culture of the Navel Orange}

New light has been thrown upon the origin of the navel orange by study of the conditions surrounding its culture at Bahia, Brazil. Interesting facts were gathered by specialists of the United States Department of Agriculture who were in search of new plants in the South American country. All the evidence points to the fact that the variety of navel orange now so largely grown in the United States first came into existence at Cabulla, a suburb of Bahia, early in the nineteenth century, as a sport from the Selecta orange. The latter variety is still grown extensively near Bahia and in other parts of Brazil, and some of the trees show a marked tendency at times to produce fruit with well-developed navels. Such fruit, however, is not seedless, though the number of seeds is relatively small. The nave variety has almost entirely supplanted the parent variety about Bahia, where it has been known for more than 100 years. In the vicinity of Rio de Janeiro but few trees of the seedless variety are grown.

It was from a plantation near Bahia, so far as can be determined, that the budded trees were obtained through which the navel orange wood was introduced into the United States. Several were shipped to the United States Department of Agriculture. Trees were grown in the department greenhouses, and others propagated from them were distributed to California and Florida. The variety proved to be unsuited to Florida conditions, but in California is it very productive and highly valued. Almost the entire present planting of the variety in that State can be traced directly back to two of the trees ent there by the Department of Agriculture in 1873

The navel orange in Brazil, unlike its descendant in California, grows under warm conditions. Seedlings of the bitter or sour orange (Citrus aurantium) are employed almost exclusively as stocks, and the navel orange wood is propagated on them by shield budding in essentially the same way that buds are propagated in the United States.

The navel orange as it occurs near Bahia is large, varying from $3 \frac{1}{2}$ to 4 inches in diameter, is yellow-green in color, and extremely juicy and sweet. Comparative studies made by the Department of Agriculture show that the Brazilian fruits have a considerably lower percentage of peel than the California fruits and somewhat less fibrous matter or "rag." The California orange, however, has a much larger percentage of both citric acid and sugar.

Bud wood from a number of the most promising strains of the Bahia navel orange trees was brought to the United States by the department's plant explorers and is being tested in California and Florida. It is pointed out by the department that because of the important effect of climate on the size and character of the fruit it is impossible to determine in advance whether strains which appear desirable in Bahia will retain their charcteristics in the United States. This can be decided only by the tests now under way.

Bulletin 445, issued by the Department of Agriculture, gives the details of the investigations of this subject that have been conducted.-U. S. Commerce Report.

Lag in U. S. Naval Radio Time Signals

TnE U. S. Naval Observatory has determined the lag of the Arlington signal to be about two hundredths of a second (.02) and that of the Key West signal to be about twenty-seven hundredths of a second (.27), this lag being due to the various relays in the telegraph lines over which the time signal passes from the Naval Observatory. The error of the time signal is generally less than onetenth of a second (.1). 